\title{
Pathophysiology of Rheumatoid Associated Lung Diseases
}

\author{
HiwotBerhanu*and Tefera Darge \\ Department of Biomedical Sciences, Institute of Health, Ethiopia
}

*Corresponding author: Hiwot Berhanu, Department of Biomedical Sciences, Institute of Health, Jimma University, Ethiopia

\begin{tabular}{|c|c|}
\hline ARTICLE INFO & ABSTRACT \\
\hline Received: August 14, 2020 & \multirow{4}{*}{$\begin{array}{l}\text { Background: Rheumatoid arthritis is a chronic progressive autoimmune multi- } \\
\text { systemic inflammatory disease that is mainly characterized by severe pain, swelling, } \\
\text { and symmetric polyarthritis. Although the joint disease is the main presentation of } \\
\text { rheumatoid arthritis, extra-articular diseases occur in approximately } 50 \% \text { of rheumatoid } \\
\text { arthritis patients, with the lung being a common site of involvement and a chief } \\
\text { contributor to morbidity and } 2 \text { nd leading cause of mortality in them. All components } \\
\text { of the lung structure are potential targets of injury including the pleura, vasculature, } \\
\text { airways, and parenchyma. Interaction of genes and environmental factors are highly } \\
\text { incriminated in self-protein citrullination and production of autoantibodies against } \\
\text { citrullinated peptides distributed throughout the body including lungs. Even though, } \\
\text { not always clinically recognized up to } 50 \% \text { of Rheumatoid arthritis patients exhibit } \\
\text { pulmonary involvement. }\end{array}$} \\
\hline Published: 㓞 September 02, 2020 & \\
\hline $\begin{array}{l}\text { tation: Hiwot Berhanu, Tefera Darge. } \\
\text { thophysiology of Rheumatoid Associat- } \\
\text { Lung Diseases. Biomed J Sci \& Tech Res } \\
\text { (1)-2020. BJSTR. MS.ID.004884. }\end{array}$ & \\
\hline ywords: Rheumatoid arthritis; Lung di & \\
\hline
\end{tabular}

\section{Short Communication}

Rheumatoid arthritis (RA) is a chronic progressive autoimmune multi-systemic inflammatory disease of unknown cause that mainly characterized by symmetric poly arthritis. It often results in articular cartilage and bone destruction which ultimately leads to functional disabilities in the long-term. Generally, in the beginning, the small joints of the hands and the feet are affected, later spreading to the larger joints of the body [1]. Rheumatoid arthritis affects about $1 \%$ of the population in developed countries. The incidence and prevalence of rheumatoid arthritis in developing countries are presumed to be lower, even though it is difficult to quantify exactly. The prevalence and incidence increase with age between 25-55years being higher in females than males and peaks at about the age of 70 then declines. RA is not only a disease of joints but also leads to a variety of extra-articular systems involvement including Cardiac, Pulmonary, Renal, Hematological, Ocular, Endocrine, Integumentary, Skeletal and Gastrointestinal tract [1,2].

The extra-articular disease occurs in approximately 50\% of patients, with the lung being a common site of extra-articular involvement and a huge contributor to morbidity and mortality in a patient suffering from RA. The lung is a frequent target of autoimmune-mediated injury in patients with rheumatic diseases [3]. The most remarkable aspect of RA lung involvement is that virtually all components of the lung structure are potential targets of injury and affect all of the structures of the lungs, including the pleura and vasculature in particular airways and parenchyma of the lungs $[4,5]$. Most lung diseases during RA occur during the first 5 years after RA diagnosis with the airway disease being the earliest manifestation [6]. Most forms EAMs of RA including RA-associated ILD and the subclinical myocarditis of RA present more insidiously with a longer subclinical period. Prevalence estimates for EAMs vary across studies due to the type of RA population sampled, but $20-40 \%$ of patients with RA were reported to have least one EAM and $10-20 \%$ were reported to have a severe EAM [7].

\section{Types of Rheumatoid Associated Lung Diseases}

Rheumatoid lung diseases are a set of lung ailments developed in rheumatoid arthritis patients. Pulmonary manifestations of rheumatoid arthritis can be categorized as:

a) Pulmonary parenchymal disease.

b) Pleural involvement. 


\section{c) Airways and pulmonary vasculature}

When evaluating a patient with a pulmonary disease of unknown etiology physicians are expected to assess for systemic and articular signs and symptoms of connective tissue disease as pulmonary manifestations sometimes precede articular manifestations [2].

\section{Parenchymal Rheumatoid Lung Diseases}

Interstitial lung diseases (ILDs) are a group of diffuse parenchymal lung disorders that affect the interstitium (the tissue and space around the alveoli). They are classified according to specific clinical, radiological, and histopathological features. A revised 2013 ATS/European Respiratory Society classification of idiopathic interstitial pneumonia categorizes them as listed below $[8,9]$. (Table 1) Pulmonary involvement in RA is frequent even though, not always clinically recognized. RA-associated ILD has the largest impact on RA morbidity and mortality across the diverse RA population. About $50 \%$ of RA patients exhibit pulmonary involvement however it fluctuates sometimes depending on the screening method used, Autopsy studies reported pleural involvement in $50 \%$ of cases, with only $10 \%$ clinically detected $[10,11]$. RA-ILD three times more common in males than in females, in contrast to most connective tissue diseases, in patients with late-onset disease, a high titer of RF, and smokers. Even though no identifiable cause for RA-ILD researchers have been used genetic, clinical and environmental factors to predict the development of lung disease in RA [12].

Table 1.

\begin{tabular}{|c|c|}
\hline Histologic patterns & $\begin{array}{c}\text { Clinical-radiological-pathologic } \\
\text { diagnosis }\end{array}$ \\
\hline $\begin{array}{c}\text { Usual Interstitial pneumonia } \\
\text { (UIP) }\end{array}$ & $\begin{array}{c}\text { (Idiopathic) pulmonary fibrosis/ } \\
\text { (cryptogenic) fibrosing alveolitis } \\
\text { (IPF/CFA) }\end{array}$ \\
\hline $\begin{array}{c}\text { Nonspecific interstitial } \\
\text { pneumonia (NSIP) }\end{array}$ & $\begin{array}{c}\text { Nonspecific interstitial pneumonia } \\
\text { (NSIP) }\end{array}$ \\
\hline $\begin{array}{c}\text { Organizing pneumonia (OP) } \\
\text { Diffuse alveolar damage (DAD) }\end{array}$ & $\begin{array}{c}\text { Organizing pneumonia (preferred } \\
\text { definition) = Bronchiolitis obliterans } \\
\text { organizing pneumonia (OP = BOOP) }\end{array}$ \\
\hline $\begin{array}{c}\text { Acute interstitial pneumonia (AIP) } \\
\text { Respiratory bronchiolitis (RB) }\end{array}$ & $\begin{array}{c}\text { Respiratory bronchiolitis interstitial } \\
\text { lung disease (RB-ILD) }\end{array}$ \\
\hline $\begin{array}{c}\text { Desquamative interstitial } \\
\text { pneumonia (DIP) }\end{array}$ & $\begin{array}{c}\text { Desquamative interstitial pneumonia } \\
\text { (DIP) }\end{array}$ \\
\hline $\begin{array}{c}\text { Lymphoid interstitial } \\
\text { pneumonia (LIP) }\end{array}$ & Lymphoid interstitial pneumonia \\
(LIP)
\end{tabular}

\section{Pathophysiology of Rheumatoid Interstitial Lung Disease}

Though, Mechanisms of RA in causing airway and parenchymal lung disease development are not well defined. several factors like host genetic predisposition, smoking, infection and premature senescence of cells are all putatively important in the development of rheumatoid lung diseases and RA $[13,14]$.

\section{Factors that Contribute to RA-ILD}

Conversion of a positively charged arginine to polar nonstandard neutral amino acid citrulline as the result of post-translational modification by peptidyl arginine deiminase isoenzymes result in protein citrullination. Genetic predisposition and environmental factors interactions are highly incriminated in self-protein citrullination resulting in the synthesis of autoantibodies against citrullinated peptides which are widely distributed throughout the body. Exposure to noxious agents, infectious agents, gut microbiome, and dietary factors may induce the self -protein citrullination and maturation of anti-cyclic citrullinated peptide autoantibody (ACPA) $[15,16]$.

\section{Genetic Predisposition}

HLA variants have a higher binding affinity to citrullinated proteins and an increasing tendency to present citrullinated peptides to immune cells. HLA-B54, HLA-DQB1*0601, HLA-B40, and HLA-DR4 has been associated with RA-ILD. The citrullination process may initially take place in mucosal sites [17]. RA-associated autoimmunity results in downstream autoantibody production and activation of $\mathrm{T}$ cell towards self-peptides causes breakdown of tolerance to autoantigens [18]. Autoantigens like citrullinated collagen and fibrinogen formed after arginine deamination. Synthesized autoantigens are preferentially bound by HLA-DRB SE proteins and are presented to T cells. Then they interact with CCP-specific B cells found at sites containing autoantigen and ultimately produce inflammatory cytokines and autoantibodies which is critical for disease progression [15]. Serum autoantibodies produced against multiple citrullinated proteins and peptides including fibrinogen, vimentin, heat shock protein 90, matrix metalloproteinase 7 and interferon-gamma inducible protein have been associated with RA-ILD [19].

Shared epitope (HLADRB1 alleles) presence indicates the expression of certain amino acids in positions 70 to 74 of the third hypervariable region of the DRB chains which increase capacity to bind to citrullinated peptides. The structural/electrostatic changes induced by PAD within these proteins render them immunogenic in a subset of patients who have a genetic predisposition and possess shared epitope [6]. HLA-DR2 alleles (HLA-DRB1*15 and HLADRB1*16) were associated with an increased risk of ILD from a cohort study conducted in Japanese people. Predisposition to bronchiectasis or emphysema in RA was associated with HLADQB1*03:01, and HLADQB1*03:02. Whereas the HLA-DRB1 shared epitope was associated with a reduced risk of ILD [20]. Specialized sentinel cells called dendritic cells bridge the innate and adaptive immune systems without directly engaging in effector activities. They recognize pathogens using pattern recognition receptors like Toll-like receptors (TLRs), and then they migrate to T cell areas of lymphoid organs to present pathogen-derived antigens to antigenspecific T cells. Activated DCs upregulate co-stimulatory molecules and produce cytokines that drive $\mathrm{T}$ cell priming and effector 
differentiation, and they activate various types of immune cells [21].

\section{Airways and Epithelial Cell Injury}

Airway and alveolar epithelial cell injury are probably the most incriminated underlying cause in the pathogenesis of lung disease in rheumatoid arthritis and an important early event that precedes the development of autoimmunity in the lung. Airway and alveolar epithelial cells are involved in body defense to inhaled substances and pathogens, which are potential primary triggers of mucosal injury. Healing and the restoration of the lung anatomy are occurred following injury normally to maintain homeostasis However, in individuals with a certain genetic predisposition, with altered mucosal microbial flora or who smoke, persistent antigenic stimulation can lead to a breach of tolerance, resulting in an adaptive immune response [14].

\section{Cigarette Smoking}

Cigarette smokers are reported to have increased expression of PAD2 in both proximal and distal airways. Increased concentrations of citrullinated peptides in BAL cells, relative to a matched cohort of healthy nonsmokers was noticed. So, the dis regulation of PAD enzymes seems an important molecular checkpoint that links environmental stressors, host genes and the development of ACPA against self-antigens [22]. Airway and interstitial lung involvement are also seen in zero-negative patients with RA [23].

\section{Gastro Esophageal Reflux Disease}

Gastro esophageal reflux disease might potentially provide another mechanism by which previously swallowed saliva containing bacteria. Gingivitis could be regurgitated and aspirated into the lungs, thereby causing airway mucosal injury and introducing the pathogen into the lower airway. In turn, these changes might promote an increase in protein citrullination and ACPA formation as the bacteria produce PAD enzymes [22].

\section{Infections and Dysbiosis}

The presence of chronic airway disease and dysbiosis could either be a primary inducer of ACPA generation and inflammation. Different studies have shown increased ACPA concentrations and a reduction in physiological markers is immensely correlated. Patients with RA who have high concentrations of ACPAs are more likely to develop ILD.ACPAs can cause injury to the lung mucosa, airways, and interstitium through several potential mechanisms. They can form immune complexes and activate cells by binding to $\mathrm{Fc}$ receptors, resulting in the release of pro-inflammatory like TNF and cytokines such as IL-6, IL-8 [2,24,25]. Increased risk of infections is shown in RA patients compared with the general population, even after adjustment for age, sex, smoking status, leukopenia, corticosteroid use, and diabetes mellitus [26]. A cellular inflammatory process initiates a secondary fibro proliferative process. This fibro proliferative process may become progressive and independent of its initiating cause result in lung fibrosis. Injury to the epithelial surface initially causes inflammation in the air spaces and alveolar walls. As the inflammation spreads to adjacent portions of the interstitium and vasculature and disease become chronic eventually leads to interstitial fibrosis. The development of irreversible scarring leads to significant derangement of ventilator function and gas exchange [27]. A form of reactive lymphoid tissue known as inducible bronchus-associated lymphoid tissue (IBALT) has been found in patients with RA-ILD and is associated with local production of several inflammatory cytokines and anti-CCP antibodies [28]. When present in high titers Both rheumatoid factor and anti-CCP have been linked to the development of ILD, Even though the mechanism is so elusive [29,30].

In some patients, citrullinated peptides may also be produced in the lungs, possibly causing an immune response. Activated fibroblasts in the lungs are differentiated into myofibroblasts ultimately produce fibrosis. Interstitial lung inflammation development explains the formation of a predominantly inflammatory disease pattern such as non-specific interstitial pneumonia [31]. Fc receptors expressed on antigen-presenting cells complexed with Antibodies against citrullinated peptides which ultimately leads to the production of pro inflammatory cytokines. Production of both Cytokines and chemokines play a crucial role in the development of RA-ILD. TNF-alpha is mainly produced by activated macrophages, lymphocytes, epithelial, and endothelial cells plays a central role in the stimulation of cell-cell adhesion, trans endothelial migration and the maintenance of cytokines and chemokines production cascade [32]. TNF-alpha also stimulates fibroblasts proliferation and triggering the expression of growth factors such as platelet-derived growth factor-(PDGF-) and transforming growth factor-beta (TGF-beta), cytokines such as interleukin- 4 (IL-4) and interleukin-13 (IL-13), and chemokines (e.g., CXCL5, CXCL8, CXCL12, and CXCL13) that further contribute to stimulating fibroblast differentiation and proliferation, thus potentially linking inflammatory and fibrotic process $[33,34]$.

PDGF-alpha is produced by a wide array of lung cells, including macrophages, fibroblasts, epithelial and endothelial cells. play a primary role in the pathogenesis of IPF, figuring among pro fibrotic and pro inflammatory molecules known to be critical in the pathogenesis of ILD, such as TGF-beta and TNF-alpha [35]. TGFbeta also induces fibroblasts' differentiation into myofibroblasts, which represent the main source of extracellular matrix in lung fibro genetic processes. Chemokines are secreted by macrophages, fibroblasts, and epithelial cells and act through fibroblast recruitment and activation. CXCL13 is a B-cells chemo attractant known to regulate lymphoid follicles organization within a tissue [36]. Matrix metalloproteinases originated from damaged epithelia perpetuate crosstalk between inflammatory and fibrotic processes by the enhancement of cellular recruitment ( $B$ and $T$ cells, macrophages, and neutrophils) and by the production of additional pro-fibrotic mediators. vascular endothelial cell growth factor 
and by the pro inflammatory milieu induce Angiogenesis which also strictly connected with different phases of the pathological processes of inflammation and fibrosis [37].

ACPA targeting citrullinated HSP90 is produced in the lung microenvironment, supporting a role for the lung in initiating relevant immune responses or spreading the ACPA repertoire [38]. Several treatment modalities for RA may induce infections, including corticosteroids, disease-modifying anti-rheumatic drugs (DMARDS), Tumor necrosis factor (TNF) antagonist, and new biotherapies. Opportunistic infections may also appear. Some are associated with lung injury others are associated with activation of latent TB. The incidence of pulmonary toxicity in patients treated with methotrexate (MTX)with doses less than 20mg per week is minimal. Recent studies have reported that methotrexate pneumonitis occurs with a dose of $5 \mathrm{mg}$ per week [39,40]. Aging alveolar epithelial cells gain the ability to secrete substances that promote the formation of tissue fibrosis in patients with a genetic susceptibility to RA. This process may explain the formation of a predominantly fibrotic disease pattern such as usual interstitial pneumonia [41]. Aberrant alveolar epithelial cells subjected to mechanical stress gain the ability to secrete a variety of substances, including growth factors, chemokines, matrix metalloproteinases, pro-coagulants, and vasoactive mediators which in turn promote the transition of fibroblasts to myofibroblasts, ultimately favoring the dysregulated deposition of extracellular matrix (ECM) components and associated to tissue fibrosis [27] (Figure 1).

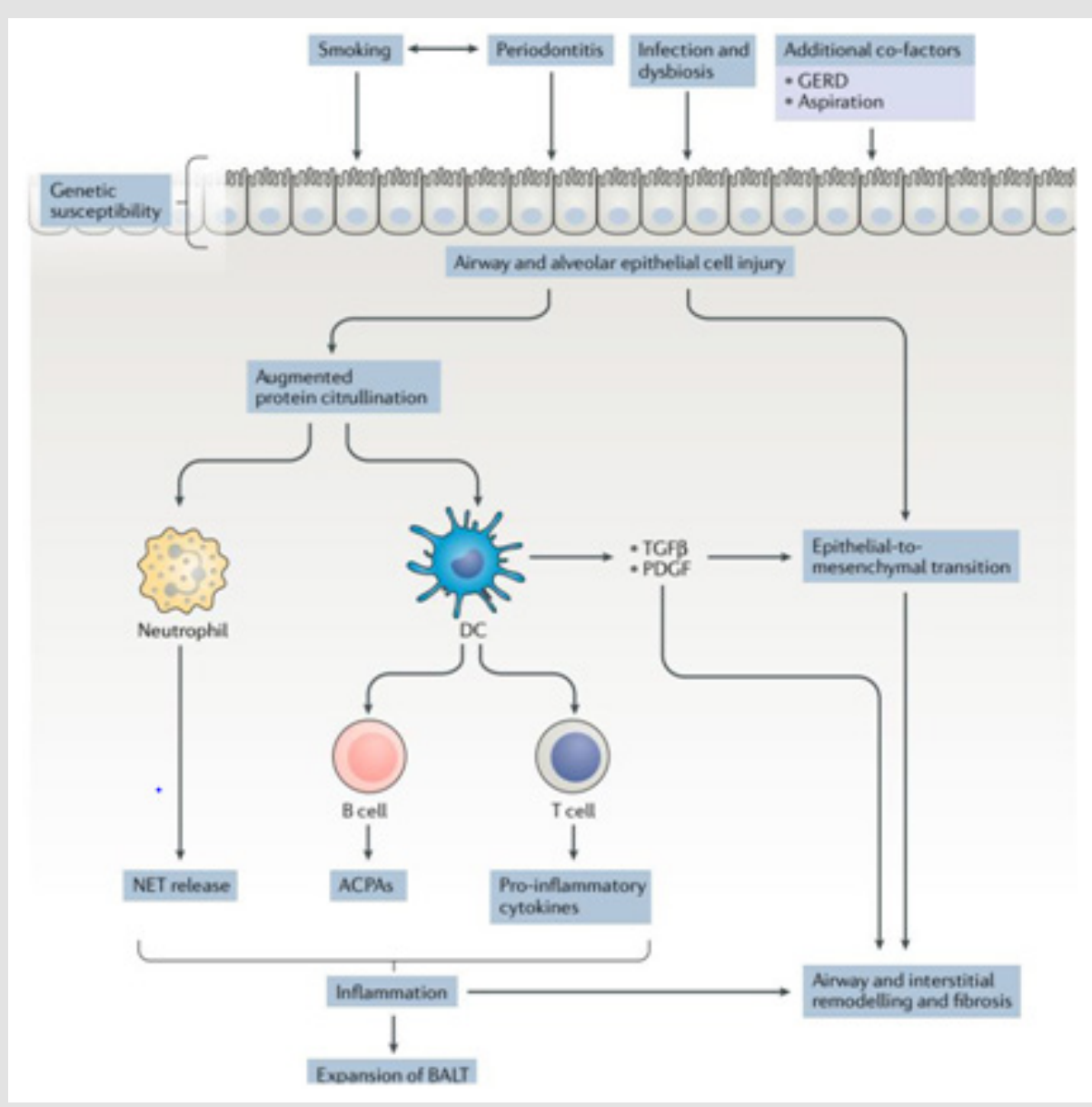

Figure 1: Schematic presentation of the proposed mechanism of rheumatoid lung diseases[14].

\section{Potential Pathways Explain the Co-existence of RA and}

\section{ILD}

Citrullination One of enzymatic post-translational modification of protein is immensely linked to the development of joint damage, Appearance immune response to citrullinated proteins in RA and presence of citrullinated protein in the lungs of RA-ILD and IPF subjects paved the way to propose potential mechanisms that explain the co-existence of RA and ILD [16,42]. a) The immune response against citrullinated peptides taking place at the joints subsequently shifts to the lungs, resulting in interstitial lung inflammation most likely a non-UIP pattern of RA-ILD

b) Individuals with UIP and genetic susceptibility to RA mount an immune response against citrullinated peptides in the lung, initiating an inflammatory process that secondarily affects the joints. 
Regardless of whether the immune response begins in the joints or the lungs, poorly defined molecular mechanisms are likely involved in shifting the immune response from one tissue compartment to the other. Plausible explanations for the shared targeting of lung and joints in RA include the formation and deposit of immune complexes as RF contributing to their deposition by its capacity to bind the Fc portion of IgG [43]. The presence of structural overlap between initiating antigens and subsequent post-translationally modified targets such as citrullinated vimentin present in both lung and synovial tissue in patients with RA [30], and the immunologic process of epitope spreading leads to a widening of the immune response spectrum [44] (Figure 2).

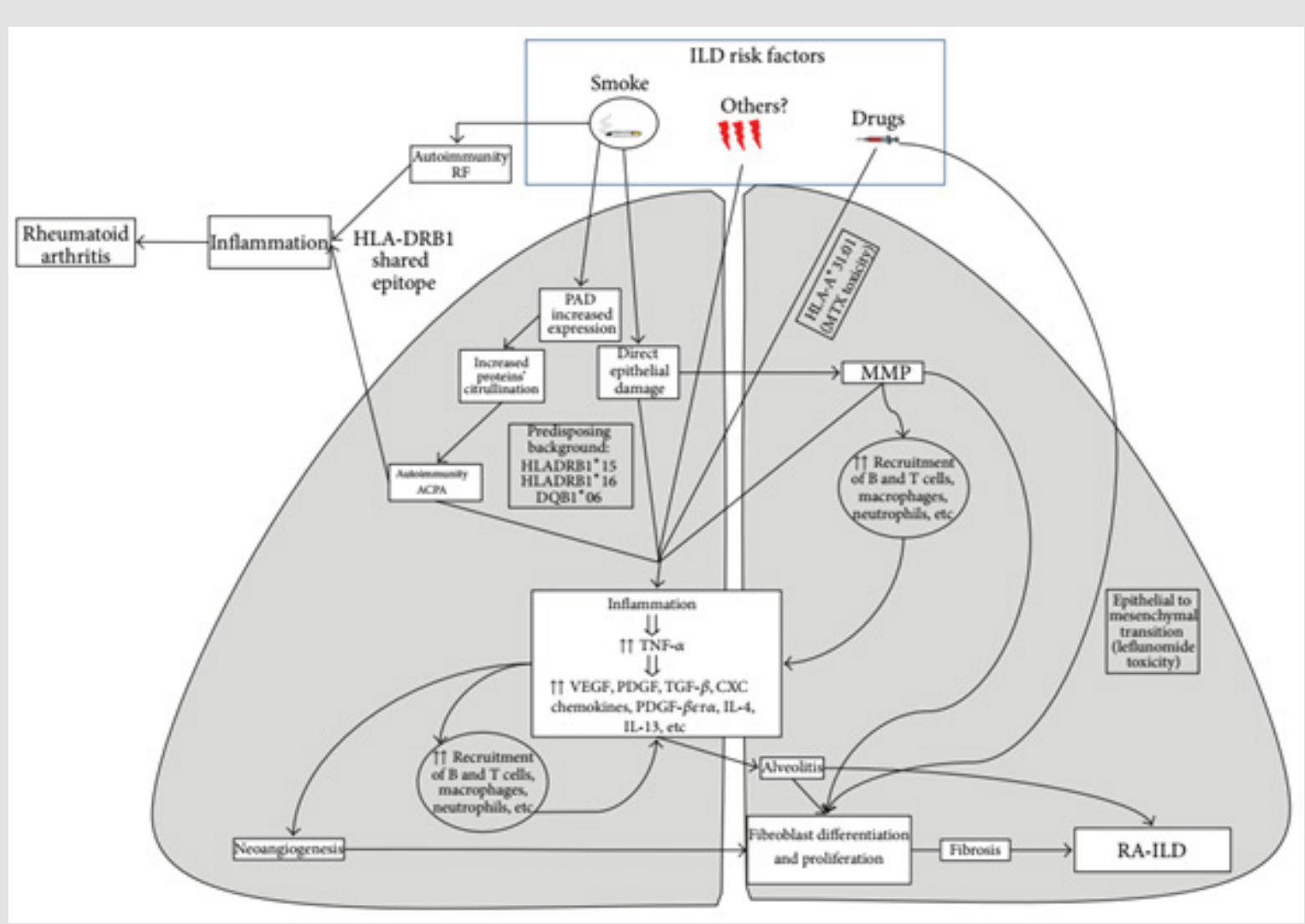

Figure 2: Pathogenesis of RA-ILD[37].

\section{Airway Involvement in Rheumatoid Arthritis}

Rheumatoid arthritis is also characterized by involvement of any part of the airway including the large airways (upper and lower) and distal small airways. The most common manifestations are bronchiectasis, bronchiolitis, airway hyper reactivity, and cricoarytenoid arthritis. Prevalence of airways disease in RA is high; it occurs in $39 \%$ to $60 \%$ of patients [45].

\section{Upper Airway Disease}

The cricoarytenoid joints are small diarthrodial joints that rotate with the vocal cords as they abduct and adduct to vary the pitch and tone of the voice. Though not disabling, the cricoarytenoid joints may become inflamed and immobilized with the vocal cords adducted to the midline, causing inspiratory stridor and upper airway obstruction [46]. Laryngeal obstruction is usually related to arthritis of the cricoarytenoid joints, less commonly a rheumatoid nodule may develop on the vocal cords [47]. An erosive mass on the cricoid cartilage causing acute upper airways obstruction with significant destruction of the surrounding structures was also described [48].

\section{Lower Airway Disease}

Follicular bronchiolitis and constrictive bronchiolitis are the two small airways disease have been described in association with RA. Follicular bronchiolitis is identified pathologically by the presence of hyperplastic lymphoid follicles with reactive germ cell centers within bronchiole walls. Constrictive bronchiolitis (obliterative bronchiolitis) is characterized by concentric narrowing of membranous and respiratory bronchioles caused by peribronchiolar inflammation and fibrosis without evidence of lymphoid hyperplasia [49]. Several studies have proposed that bronchi/bronchioles are one of the main targets of autoimmunity in RA patients. Bronchiolar inflammation may secondarily induce mucosal edema, which eventually leads to the development of small airway obstruction. This Chronic colonization, secondary persistent 
inflammation, and progressive lung injury may contribute to the frequent development of airway obstruction during the disease course [45]. Bronchiectasis may result from recurrent infections, retraction in interstitial lung diseases (traction bronchiectasis) or progression of lymphocytic/constrictive bronchiolitis in RA patients.

\section{Acknowledgement}

We would like to express our appreciations to Jimma University who helped us to undertake this study.'

\section{References}

1. Dan LL, Anthony FS, Dennis KL, Stephen HL, Larry JJ, Joseph LE (2018) Harrison's Principles of Internal Medicine. 20 ${ }^{\text {th }}$ (Edn): McGraw Hill Medical pp. 2527-2528.

2. Shaw M, Collins BF, Ho LA, Raghu G (2015) Rheumatoid arthritisassociated lung disease pp. 1-16.

3. C Turesson, WMO Fallon, CS Crowson, SE Gabriel ELM (2003) Extraarticular disease manifestations in rheumatoid arthritis 62(8): 722-727.

4. Fischer A, Bois R (2012) Interstitial Lung Disease 2 Interstitial lung disease in connective tissue disorders 380(9842): 689-698.

5. Yunt ZX, Solomon JJ (2015) Lung Disease in Rheumatoid Arthritis Zulma 41(2):225-236

6. Demoruelle MK, Weisman MH, Simonian PL, Lynch DA, Sachs PB, et al. (2012) Airways Abnormalities and Rheumatoid Arthritis - Related Autoantibodies in Subjects Without Arthritis: Early Injury or Initiating Site of Autoimmunity 64(6): 1756-1761.

7. Prete M, Racanelli V, Digiglio L, Vacca A, Dammacco F, et al. (2011) Autoimmunity Reviews Extra-articular manifestations of rheumatoid arthritis: An update. Autoimmun Rev 11(2):123-131.

8. Travis WD, Costabel U, Hansell DM, King TE, Lynch DA, et al. (2013) American Thoracic Society Documents An Official American Thoracic Society / European Respiratory Society Statement: Update of the International Multidisciplinary Classification of the Idiopathic Interstitial Pneumonias 188: 733-748.

9. Tsuchiya Y, Takayanagi N, Sugiura H, Miyahara Y, Tokunaga D, et al (2011) Lung diseases directly associated with rheumatoid arthritis and their relationship to outcome. ER Journal 37(6): 1411-1417.

10. Bendstrup E, Møller J, Kronborg-white S, Prior TS, Hyldgaard C (2019) Interstitial Lung Disease in Rheumatoid Arthritis Remains a Challenge for Clinicians.

11. Bongartz T, Nannini C, Medina-velasquez YF, Achenbach SJ, Crowson CS, et al. (2010) Incidence and Mortality of Interstitial Lung Disease in Rheumatoid Arthritis 62(6): 1583-1591.

12. Amital A, Shitrit D, Adir Y (2011) Quarterly Medical Review.

13. Vassallo R, Luckey D, Behrens M, Madden B, Luthra H, et al. (2014) Cellular and humoral immunity in arthritis are profoundly influenced by the interaction between cigarette smoke effects and host HLA-DR and DQ genes. Clin Immunol 152(1-2): 25-35.

14. Wang D, Matteson EL, Vassallo R (2019) Mechanisms of lung disease development in rheumatoid arthritis.

15. Lang F. Encyclopedia of Molecular Mechanisms of Disease 1.

16. Guo Q Wang Y, Xu D, Nossent J, Pavlos NJ, et al. (2018) Rheumatoid arthritis: pathological mechanisms and modern pharmacologic therapies 6:15.

17. Demoruelle MK, Deane KD, Holers VM (2014) When and where does inflammation begin in rheumatoid arthritis? 26(1): 64-71.
18. Klareskog L, Stolt P, Lundberg K, Ka H, Bengtsson C, Grunewald J, et al. (2006) A New Model for an Etiology of Rheumatoid Arthritis Smoking May Trigger HLA - DR ( Shared Epitope )- Restricted Immune Reactions to Autoantigens Modified by Citrullination. Arthritis Rheum 54(1): 3846.

19. Giles JT, Danoff SK, Sokolove J, Wagner CA, Winchester R, et al. (2014) Association of fine specificity and repertoire expansion of anticitrullinated peptide antibodies with rheumatoid arthritis associated interstitial lung disease. Ann Rheum Dis 73(8): 1487-1494.

20. Furukawa H, Oka S, Shimada K, Sugii S, Ohashi J, et al. (2012) Association of Human Leukocyte Antigen with Interstitial Lung Disease in Rheumatoid Arthritis: A Protective Role for Shared Epitope. Plos One $7(5): 33133$.

21. Steinman RM, Steinman RM (2011) Decisions About Dendritic Cells: Past, Present and Future.

22. Makrygiannakis D, Hermansson M, Ulfgren A, Nicholas AP, Zendman AJW, et al. Smoking increases peptidylarginine deiminase 2 enzyme expression in human lungs and increases citrullination in BAL cells. BMJ 67: 1488-1493.

23. Zhang Y, Li H, Wu N, Dong X, Zheng Y (2017) Retrospective study of the clinical characteristics and risk factors of rheumatoid arthritisassociated interstitial lung disease. Clin Rheumatol 36(4): 817-823.

24. Wilsher M, Voight L, Milne D, Teh M, Good N, et al. (2012) Prevalence of airway and parenchymal abnormalities in newly diagnosed rheumatoid arthritis. Res Medicine 106(10): 1441-1446.

25. Clavel C, Nogueira L, Laurent L, Iobagiu C, Vincent C, et al. (2008) Induction of Macrophage Secretion of Tumor Necrosis Factor Through Fc Receptor IIa Engagement by Rheumatoid Arthritis - Specific Autoantibodies to Citrullinated Proteins Complexed With Fibrinogen. Arthritis Rheum 58(3): 678-688.

26. Doran MF, Crowson CS, Pond GR, Fallon WMO, Gabriel SE (2002) Frequency of Infection in Patients With Rheumatoid Arthritis Compared With Controls. BMJ 46(9): 2287-2293.

27. Selman M, Pardo A, Barrera L, Estrada A, Watson SR, et al. (2005) Gene Expression Profiles Distinguish Idiopathic Pulmonary Fibrosis from Hypersensitivity Pneumonitis.

28. Rangel-moreno J, Selman M, Randall TD, Rangel-moreno J, Hartson L, et al. (2006) Inducible bronchus-associated lymphoid tissue (iBALT) in patients with pulmonary complications of rheumatoid arthritis. Find the latest version : Inducible bronchus-associated lymphoid tissue (iBALT) in patients with pulmonary complications of rheumatoid arthritis 116(12): 3183-3194.

29. Aubart F, Crestani B, Nicaise-roland P, Bollet C, Dawidowicz K, et al. (2011) High Levels of Anti-Cyclic Citrullinated Peptide Autoantibodies Are Associated with Co-occurrence of Pulmonary Diseases with Rheumatoid Arthritis High Levels of Anti-Cyclic Citrullinated Peptide Autoantibodies Are Associated with Co-occurrence of Pulmonary Diseases with Rheumatoid Arthritis. J Rheumatol 38(6): 979-982.

30. Ytterberg AJ, Joshua V, Reynisdottir G, Tarasova NK, Rutishauser D, et al. (2015) Shared immunological targets in the lungs and joints of patients with rheumatoid arthritis: identification and validation. Ann Rheum Dis 74(9): 1772-1777.

31. Paulin F, Babini A, Mamani M, Mercado J, Caro F (2017) Practical Approach to the Evaluation and Management of Rheumatoid Arthritis-Interstitial Lung Disease Based on its Proven and Hypothetical Mechanisms. Rev Invest Clin 69(5): 235-242.

32. Keith RC, Powers JL, Redente EF, Sergew A, Martin J, et al. (2012) A novel model of rheumatoid arthritis-associated interstitial lung disease in SKG mice pp. 55-66.

33. Chen J, Shi Y, Wang X, Huang H, Ascherman D (2013) Asymptomatic Preclinical Rheumatoid Arthritis-Associated Interstitial Lung Disease. E Pub 2013: 10-15. 
34. Vasakova M, Striz I, Slavcev A, Jandova S, Dutka J, et al. (2007) Correlation of IL-1alpha and IL-4 Gene Polymorphisms and Clinical Parameters in Idiopathic Pulmonary Fibrosis. J Immunology 65(3): 265-270.

35. Agostini C, Gurrieri C (2006) Chemokine/Cytokine Cocktail in Idiopathic Pulmonary Fibrosis. Proc Am Thorac Soc 3(4): 357-363.

36. Manzo A, Vitolo B, Humby F, Caporali R, Jarrossay D, et al. (2008) Mature Antigen-Experienced T Helper Cells Synthesize and Secrete the B Cell Chemoattractant CXCL13 in the Inflammatory Environment of the Rheumatoid Joint. Arthritis Rheum 58(11): 3377-3387.

37. Cavagna L, Monti S, Grosso V, Boffini N, Scorletti E, et al. (2013) The Multifaceted Aspects of Interstitial Lung Disease in Rheumatoid Arthritis.

38. Harlow L, Gochuico BR, Rosas IO, Doyle TJ, Osorio JC, et al. (2014) Anti-citrullinated heat shock protein 90 antibodies identified in bronchoalveolar lavage fluid are a marker of lung-specific immune responses. Clin Immunol [Internet] 155(1): 60-70.

39. Fragoulis G, Nikiphorou E, Larsen J, Korsten P, Conway R (2019) The diagnosis and treatment ivorlanoivol.

40. Carmona L, Rodrı V, Martı E (2003) Treatment of Rheumatoid Arthritis With Tumor Necrosis Factor Inhibitors May Predispose to Significant Increase in Tuberculosis Risk. Arthritis Rheum 48(8): 2122-2127.

41. Rosas IO (2015) phenotypic traits suggest overlapping disease mechanisms 67(5): 280-286

\section{ISSN: 2574-1241}

DOI: $10.26717 /$ BJSTR.2020.30.004884

Hiwot Berhanu. Biomed J Sci \& Tech Res

(C) This work is licensed under Creative Commons Attribution 4.0 License

Submission Link: https://biomedres.us/submit-manuscript.php
42. Bongartz T, Cantaert T, Atkins SR, Harle P, Myers JL, et al. (2007) Citrullination in extra-articular manifestations of rheumatoid arthritis (2006): 70-75.

43. Sokolove J, Johnson DS, Lahey LJ, Wagner CA, Cheng D, et al. (2014) Rheumatoid Factor as a Potentiator of Anti - Citrullinated Protein Antibody - Mediated Inflammation in Rheumatoid Arthritis. Arthritis Rheum 66(4): 813-821.

44. Shlomchik MJ, Craft JE, Mamula MJ (2001) positive feedback in systemic autoimmune disease 1 .

45. Hassan WU, Keaney NP, Holland CD, Kelly CA (1994) Bronchial reactivity and airflow obstruction in rheumatoid arthritis. Ann Rheum Dis 58(3): 511-514.

46. Segebarth PB, Limbird TJ (2007) Case Report Perioperative Acute Upper Airway Obstruction Secondary to Severe Rheumatoid Arthritis. J of Arthroplasty 22(6): 916-919.

47. Webb J (1972) Rheumatoid nodules of the vocal folds pp. 122-125

48. Lawry GV, Finerman ML, Hanafee WN, Mancuso AA, Fan PT, et al. (1984) LARYNGEAL INVOLVEMENT IN RHEUMATOID ARTHRITIS A Clinical, Laryngoscopic and Computerized Tomographic Study. Arthritis Rheum 27(8): 873-882

49. Pipavath SJ, Brown KK, Newell JD, Sj P, Da L, et al. (2005) Radiologic and Pathologic Features of Bronchiolitis. AJR 185(2): 354-363.

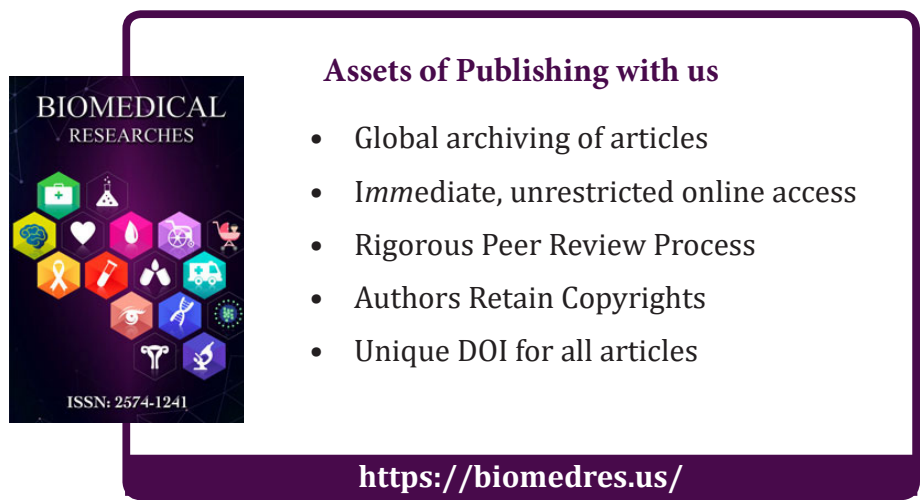

